\title{
Agglomeration of Return Fines of Sinter for Blast Furnace Raw Materials
}

\author{
Yasushi OGASAWARA, ${ }^{1 * *}$ Takeshi SATO, ${ }^{2)}$ Jun ISHII, ${ }^{1)}$ Ryota MURAI ${ }^{1)}$ and Shiro WATAKABE ${ }^{3)}$ \\ 1) Steel Research Laboratory, JFE Steel Corporation, 1 Kawasaki-cho, Chuo-ku, Chiba, 260-0835 Japan. \\ 2) Ironmaking Technology Dept., JFE Steel Corporation, 2-2-3 Uchisaiwaicho, Chiyoda-ku, Tokyo, 100-0011 Japan. \\ 3) Technology Planning Dept., JFE Steel Corporation, 2-2-3 Uchisaiwaicho, Chiyoda-ku, Tokyo, $100-0011$ Japan.
}

(Received on March 27, 2019; accepted on May 22, 2019; originally published in Tetsu-to-Hagané, Vol. 104, 2018, No. 5, pp. 253-257)

\begin{abstract}
Return fines of sinter were agglomerated with a binder material such as cement and fine powder of blast furnace slag in order to use the agglomerates as raw materials in the blast furnace. Reduction tests of the agglomerates were carried out to investigate the high temperature properties of the agglomerates. The following findings were obtained. The agglomerates have lower RDI (RDI $<20 \%$ ) than sinter because sinter, which consists of brittle glassy silicate, was arranged discretely in the agglomerates and bonded by the soft materials of the binder, and as a result, size degradation during reduction was prevented. The agglomerates have higher $\mathrm{RI}(\mathrm{DI}>70 \%)$ than sinter due to the high abundance ratio of fine pores in the agglomerates. Moreover, in comparison with sinter, the agglomerates also have equal or greater strength after reduction at $700^{\circ} \mathrm{C}$ and $900^{\circ} \mathrm{C}$ because solid phase sintering was promoted by adding ultrafine iron oxide powder. Therefore, as a blast furnace raw material, the permeability and reducibility of the agglomerates of return fines of sinter are superior to those of conventional sinter. This concept is considered to be effective for utilizing sinter fines as blast furnace raw materials in a high pulverized coal rate and low coke rate operation.
\end{abstract}

KEY WORDS: agglomeration; return fines; RDI; RI; strength after reduction.

\section{Introduction}

In the sintering process, virgin raw materials such as iron ore and limestone are used as the main raw materials, and powder coke as an agglomerating material and return fines of sinter, which are undersize sinter products, are blended as recycled raw materials. If the ratio of return fines of sinter increases, the yield of the sinter process will decrease, ${ }^{1)}$ and $\mathrm{CO}_{2}$ emissions will increase due to the excess energy consumption necessary to sinter the return fines again and the increased use of powder coke as an agglomerating material. From these viewpoints, the ratio of return fines of sinter should be decreased, but the ratio of return fines of sinter to virgin raw material remains high, at 10 to $20 \%$.

To address these problems, return fines of sinter with sizes from 1 to $5 \mathrm{~mm}$ subjected to size selection were used directly in a blast furnace, and the yield of the sinter process was increased..$^{2-4)}$ For example, Nakashima et al. reported that the yield of the sinter process was increased by $10 \%$ by using return fines of sinter directly in the blast furnace under the condition that the ratio of return fines of sinter to the iron source for the blast furnace was around $20 \%$. However, because the size of return fines of sinter is smaller than that of the other iron source for the blast furnace, the

* Corresponding author: E-mail: ya-ogasawara@jfe-steel.co.jp DOI: https://doi.org/10.2355/isijinternational.ISIJINT-2019-165 permeability of the blast furnace is deteriorated by direct use of return fines. Recently, there has been an orientation toward lower coke rate and higher pulverized coke rate blast furnace operation, but as a result, it is more difficult to secure permeability in the blast furnace. For this reason, a large amount of return fines of sinter is not used in current blast furnace operation.

In contrast, if return fines of sinter can be agglomerated and used as raw materials for the blast furnace, the permeability in blast furnace is not deteriorated. Thus, an agglomeration method for return fines of sinter by a cold process should be studied.

Various non-fired agglomeration methods for use of these agglomerates as a raw material for the blast furnace have been studied since the 1970s. For example, cold-bond pellets consisting of fine powder combined with iron sand, ore and iron-making dust or comparatively coarse powder ore under $8 \mathrm{~mm}$ were agglomerated with a cement binder and used in a real blast furnace. ${ }^{5,6)}$ Moreover, a large amount of non-fired carbonaceous-material-containing agglomerated ore was used in a real blast furnace with the aim of promoting reduction by arranging the ore and coke in close proximity and utilizing the gasification reaction of the coke. ${ }^{7,8)}$ Although the conditions for agglomerating non-fired carbonaceous-material-containing agglomerated ore, such as the diameter and blending ratio of the raw materials, were optimized, ${ }^{9)}$ the main raw material of this 
non-fired agglomerated ore was ironmaking dust, and the conditions for agglomerating return fines of sinter have not been studied. Furthermore, the properties of agglomerates of return fines of sinter as a raw material for the blast furnace have also not been studied. Therefore, in this research, not only an agglomeration method for return fines of sinter in a cold process, but also the high temperature properties of the agglomerates were studied, and the process of using the agglomerates as raw material for the blast furnace was evaluated.

\section{Agglomeration Method}

The outline of a new agglomeration process for return fines of sinter is shown in Fig. 1. A pan pelletizer, which is used to manufacture pellets as a raw material for the blast furnace, was also adopted in this new process in order to agglomerate return fines of sinter in large quantities. However, how to agglomerate return fines of sinter is a problem because the return fines are comparatively coarse and thus are difficult to agglomerate directly. Furthermore, since the wettability of the return fines with water is poor in comparison with that of iron ore, it is more difficult to agglomerate return fines of sinter than powder iron ore. In order to solve the problem of the agglomeration method, the particle size distribution of the raw material of the agglomerates was adjusted by adding finer raw material to coarser return fines of sinter. As a result, the porosity of the raw material was minimized and the binder effect among the raw material particles was improved. The target particle size distribution of the raw material for a fine-filled structure was obtained based on Eq. (1) from Andreasen's equation, and the compounding ratio of the return fines of sinter and the finer raw material was decided by the target particle size distribution.

$$
\mathrm{P}=100 \times(\mathrm{d} / \mathrm{D})^{\mathrm{q}}
$$

$\mathrm{P}(\%)$ : Cumulative volume ratio

$\mathrm{D}(\mathrm{m})$ : Maximum diameter of particle

$\mathrm{d}(\mathrm{m})$ : Diameter of particle

q: Constant $(=0.25)$

The influence of adjusting the particle size distribution by Eq. (1) on the strength of the agglomerates was studied. Two types of agglomerates were prepared by agglomeration with $10 \%$ of alumina cement, one using a raw material whose size was only under $0.15 \mathrm{~mm}$, and the other using a raw material whose size was under $4 \mathrm{~mm}$ and was adjusted based on Eq. (1). The cold strengths of these two types of agglomerates were compared after curing for 1 day. As shown in Fig. 2, the cold strength of the agglomerates made from the raw material with a size distribution adjusted based on Eq. (1) was $50 \mathrm{kgf} /$ piece, and was more than 3 times higher than that of the agglomerates made from the raw material whose size only under $0.15 \mathrm{~mm}$.

Pellet feed, which is generally used as an iron source, was added to the return fines of sinter as a finer raw material to achieve the target particle size distribution obtained from Eq. (1), and ultrafine iron oxide powder was also added to in order to increase hot strength by solid phase sintering. The particle size distribution of each raw material is shown in Fig. 3. The size of return fines of sinter is more than 100 times as large as that of the pellet feed, and the size of ultrafine iron oxide powder is less than 0.1 times that of the pellet feed. The compounding ratio of the return fines of sinter, pellet feed and ultrafine iron oxide powder required to satisfy the target particle size distribution according to Eq. (1) was calculated. The obtained compounding ratio of the return fines of sinter, pellet feed and ultrafine iron ore powder was $79 \%, 14 \%$ and $7 \%$ respectively. The particle size distribution of the raw material after compounding is shown in Fig. 3, together with the target particle size distribution.

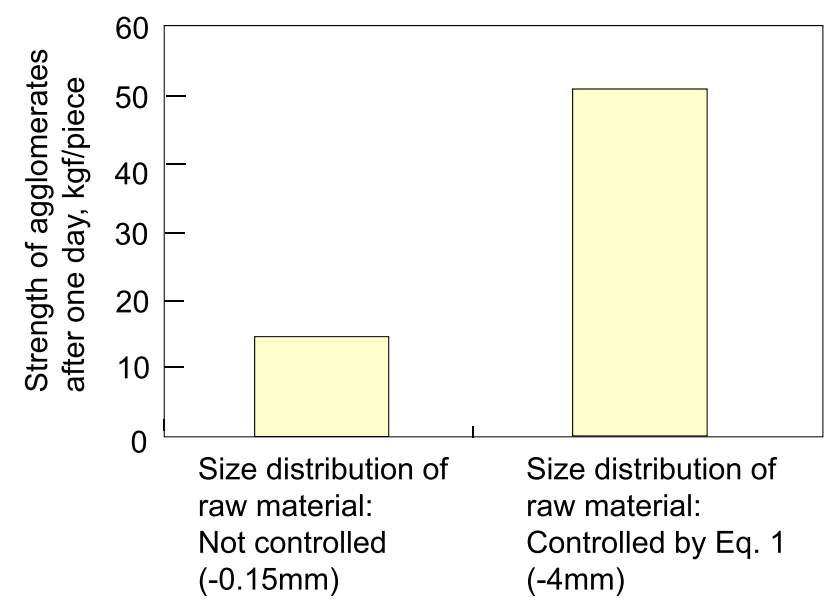

Fig. 2. Effect of controlling size distribution on strength of agglomerates. (Online version in color.)

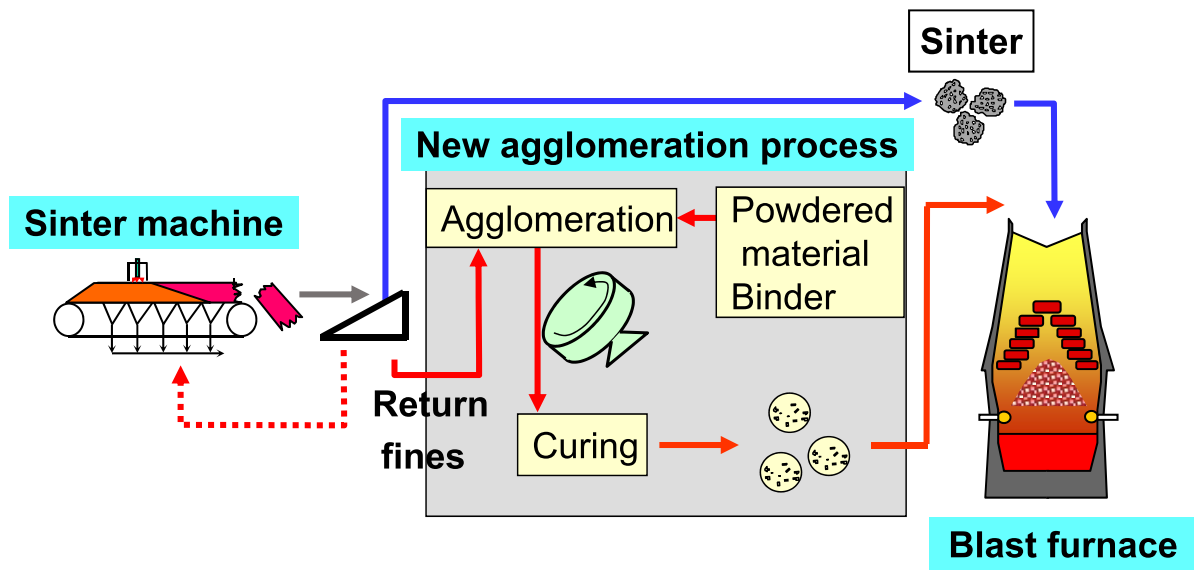

Fig. 1. Schematic illustration of new agglomeration process flow. (Online version in color.) 
The raw material was mixed with this compounding ratio, a binder material was added, and the mixture was agglomerated with a pan pelletizer having a diameter of $1200 \mathrm{~mm}$.

The ultrafine iron ore powder was added not only to increase the filling rate, but also to increase hot strength by solid phase sintering. The relationship between the heat-treatment temperature and the index of strength of the agglomerates is shown in Fig. 4. In the case without addition of the ultrafine powder, the strength of the agglomerates decreased because the cement and powder of blast furnace slag were added as binder materials, and cement bonding decreased with increasing heat-treatment temperature. Here, the cement and powder of blast furnace slag were adopted as binder materials from the viewpoints of manufacturing cost and blast furnace operation. On the other hand, in the case with addition of ultrafine iron oxide powder, the strength drop with higher heat-treatment temperatures was gentle over $600^{\circ} \mathrm{C}$, and strength increased at temperatures over $800^{\circ} \mathrm{C}$. This improvement seems to be the result of solid phase sintering by the ultrafine iron oxide powder. Thus, agglomerates with high strength from low to high tempera-

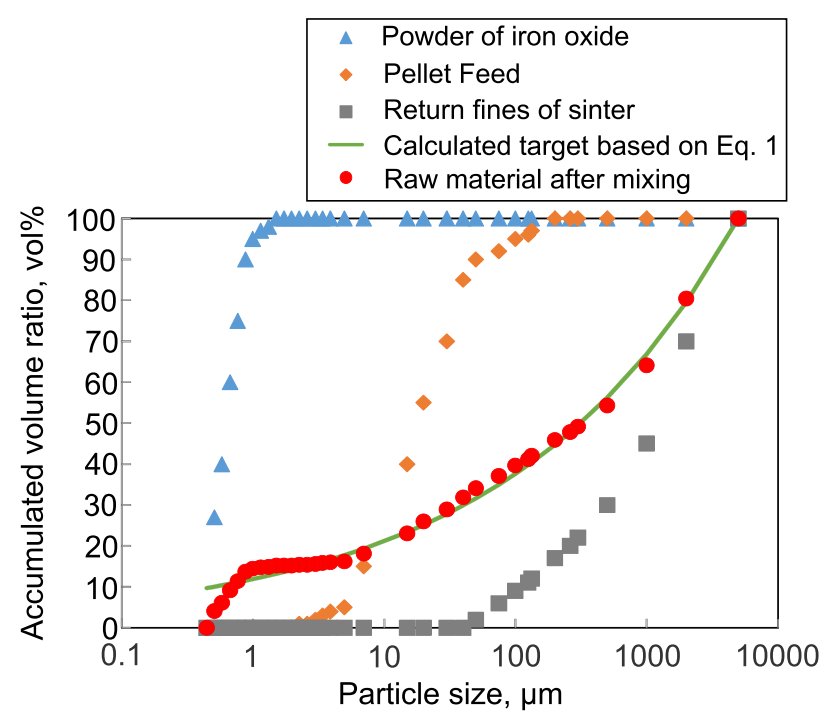

Fig. 3. Size distribution of raw materials for agglomerates of return fines. (Online version in color.)

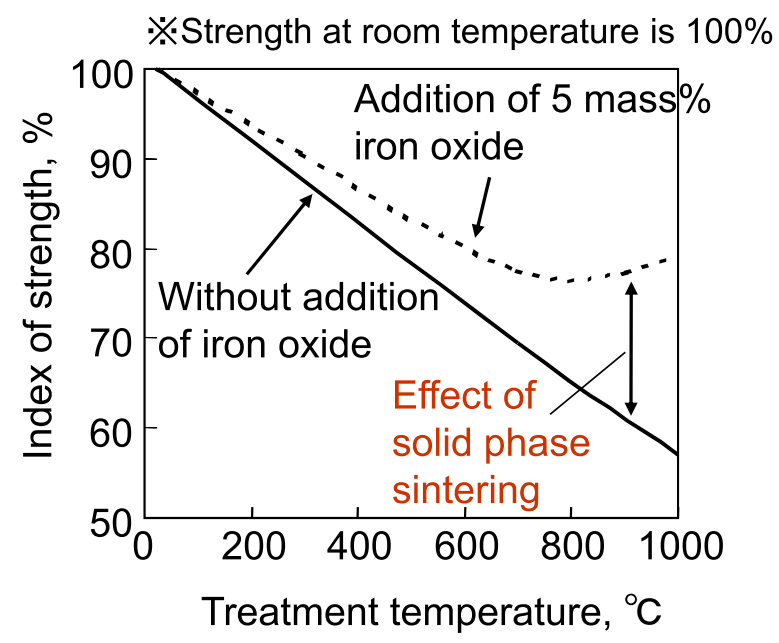

Fig. 4. Influence of treatment temperature on strength of agglomerates of return fines. (Online version in color.) tures were obtained.

\section{Reduction Experiment}

The JIS-RDI, RI and compressive strength after a reduction test with a $\mathrm{CO}-\mathrm{CO}_{2}$ atmosphere of the new agglomerates of return fines of sinter (hereafter referred to as "new agglomerates") obtained by the method described in Chapter 2 were evaluated. The composition of the raw material for the new agglomerates is shown in Table 1. In order to hold down the increase in manufacturing costs and the slag rate in blast furnace operation, $4 \%$ or $8 \%$ of powder blast furnace slag and cement were used, and the high temperature properties of the obtained new agglomerates were evaluated.

In the RI test, the combined water generated by the hydration reaction of cement has an influence on RI. Therefore, the reduction ratio was calculated as follows: First, the amount of weight reduction when $\mathrm{N}_{2}$ gas was introduced at the same temperature and flow rate as in the JIS-RI test was measured, and the reduction rate was then calculated by eliminating that amount of weight reduction from the amount of weight reduction in the JIS-RI test.

The obtained RI and JIS-RDI of the new agglomerates are shown in Fig. 5 in comparison with the other blast furnace raw materials. The new agglomerates have higher RI and lower JIS-RDI compared with sinter used as the raw material for the new agglomerates, and a similar tendency

Table 1. Composition of raw material in agglomerates of return fines.

\begin{tabular}{cccccc}
\hline & $\begin{array}{c}\text { Sinter } \\
\text { fines }\end{array}$ & $\begin{array}{c}\text { Pellet } \\
\text { feed }\end{array}$ & $\begin{array}{c}\text { Iron } \\
\text { oxide }\end{array}$ & Cement & BF Slag \\
\hline $\begin{array}{c}\text { Composition 1 } \\
\text { (Binder: 4 mass } \%)\end{array}$ & $76.2 \%$ & $13.6 \%$ & $6.3 \%$ & $1.0 \%$ & $3.0 \%$ \\
$\begin{array}{c}\text { Composition 2 } \\
\text { (Binder: 8 mass } \%)\end{array}$ & $73.0 \%$ & $13.0 \%$ & $6.0 \%$ & $2.0 \%$ & $6.0 \%$ \\
\hline
\end{tabular}

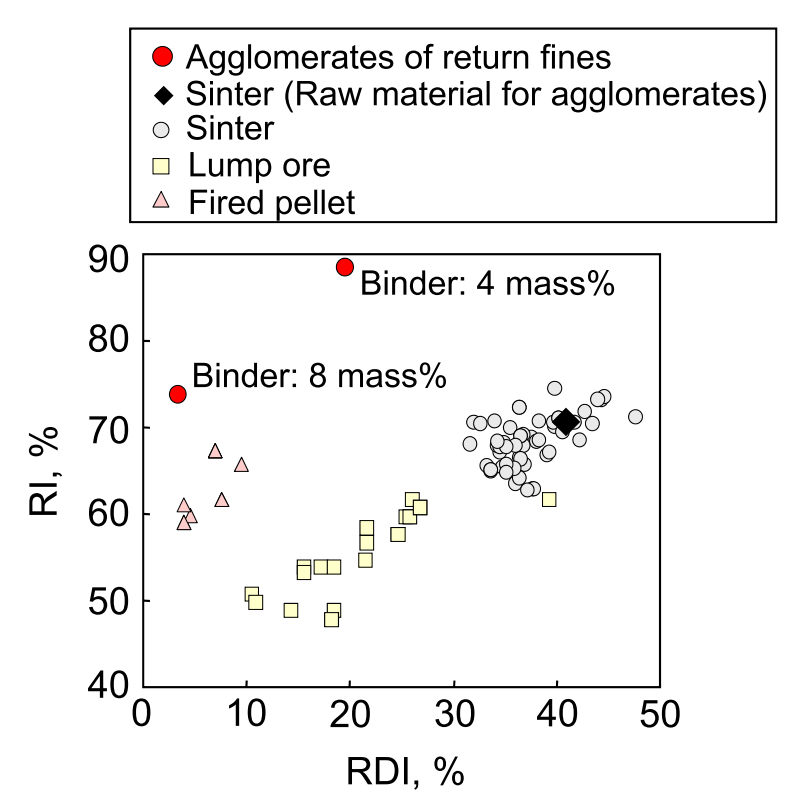

Fig. 5. Comparison of high temperature property between agglomerates of return fines and other raw materials for blast furnace. (Online version in color.) 
has also been seen in comparison with other sinter. Since higher RI and lower JIS-RDI are favorable conditions for blast furnace operation, the high temperature properties of the new agglomerates are greatly improved compared with the sinter used as the raw material.

The relationship between JIS-RDI and the reduction degree in the JIS-RDI test is shown in Fig. 6. The JIS-RDI of sinter is increased by increasing the reduction degree, and JIS-RDI is low when reducibility of the sinter is low. On the other hand, the JIS-RDI of the new agglomerates is lower than that of the sinter, even though its reduction ratio is higher than that of the sinter. As one of the factors in the decrease in the JIS-RDI of the new agglomerates, it can be pointed out that ultrafine iron oxide and pellet feed, which are difficult to be disintegrated during reduction, were used as raw materials for the new agglomerates. Even assuming that the ultrafine iron oxide and pellet feed are not disintegrated at all during reduction, the JIS-RDI of the new agglomerates is decreased to $32 \%$ from the $40 \%$ JIS-RDI of the sinter because the sum of the ratio of the ultrafine iron oxide and pellet feed is about $20 \%$. Nevertheless, the JIS-RDI of the return fines of sinter is decreased to $20 \%$. It is considered that the change of the structure of the new agglomerates by cold agglomeration plays a major role in the decrease of JIS-RDI.

Next, the influence of the raw material composition on JIS-RDI was investigated. It is known that increasing the ratio of gangue components decreases JIS-RDI, because gangue components decrease reducibility. ${ }^{11)}$ It is also known that the pore diameter in sinter is increased by increasing the content of alumina in the sinter because the amount of fused materials is reduced, ${ }^{12)}$ and furthermore, microcracks are generated in the grains by hematite containing alumina. ${ }^{13)}$ Therefore, RDI is increased by an increase of the alumina content. Based on this knowledge, the relationship between the content of $(\% \mathrm{CaO})+\left(\% \mathrm{SiO}_{2}\right)+(\% \mathrm{MgO})-$ $\left(\% \mathrm{Al}_{2} \mathrm{O}_{3}\right)$ in the raw material on JIS-RDI was investigated. The results are shown in Fig. 7. Both in the case of sinter and the new agglomerates, JIS-RDI is decreased by

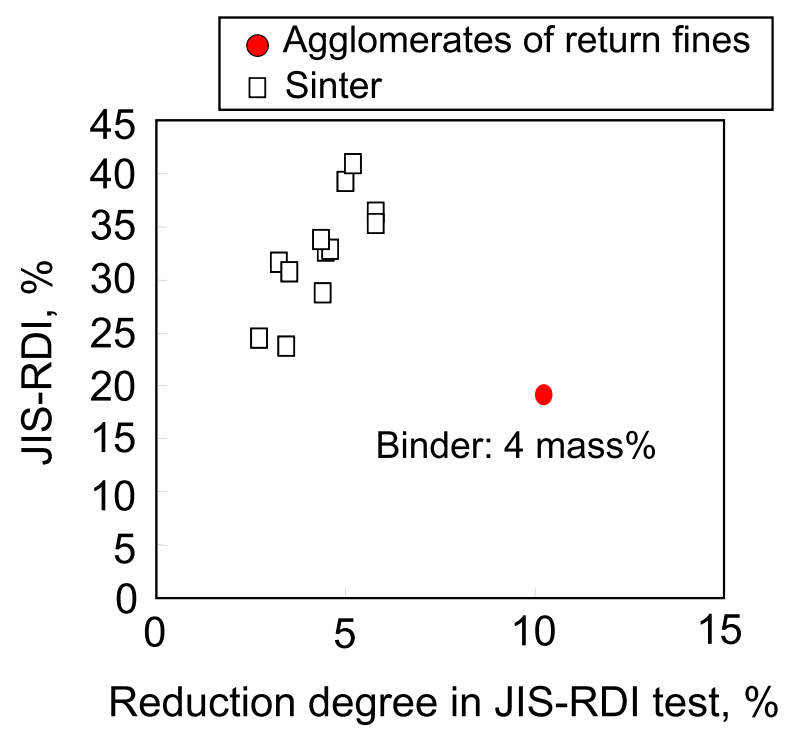

Fig. 6. Relationship between reduction degree and RDI in JISRDI test. (Online version in color.) increasing $(\% \mathrm{CaO})+\left(\% \mathrm{SiO}_{2}\right)+(\% \mathrm{MgO})-\left(\% \mathrm{Al}_{2} \mathrm{O}_{3}\right)$ in the raw material, and the JIS-RDI of the new agglomerates is lower than that of sinter when compared in the same $(\% \mathrm{CaO})+\left(\% \mathrm{SiO}_{2}\right)+(\% \mathrm{MgO})-\left(\% \mathrm{Al}_{2} \mathrm{O}_{3}\right)$. Because the new agglomerates were manufactured by a cold process, the gangue in the new agglomerates works as a binder so has a different influence compared to the influence in sinter. However, when compared at the same amount of gangue, the JIS-RDI of the new agglomerates is lower than that of the sinter.

In order to investigate the mechanism of the improvement in reduction degradation of the new agglomerates, the structures of the new agglomerates before and after reduction at $550^{\circ} \mathrm{C}$ were observed and compared with those of sinter. The reduction test was carried out with a duration of $30 \mathrm{~min}$ at $550{ }^{\circ} \mathrm{C}$ with $25 \% \mathrm{CO}-25 \% \mathrm{CO}_{2}-50 \% \mathrm{~N}_{2}$ mixed gas in order to simulate the gas atmosphere in the upper part of a blast furnace. The results are shown in Fig. 8. In sinter, mainly hematite and calcium ferrite are observed before reduction, and cracks that occur after reduction are spread over the whole matrix, which is composed of glassy silicate. On the other hand, in the new agglomerates, return fines of sinter, which have the same structure as sinter, are joined by the binder before reduction, and cracks initiate in the area of the return fines but do not propagate into the binder area. In a stochastic analysis of crack propagation in sinter, Sakamoto et al. ${ }^{14)}$ reported that glassy slag after melting had a fragile structure and the crack propagation distance was long. Although the sinter in the new agglomerates is composed of fragile glassy silicate, it is estimated that the macrostructure of the agglomerates is not fragile because the sinter is arranged discretely and is joined by the binder.

In order to evaluate the brittleness characteristics of the return fines of sinter and binder in the new agglomerates, an indentation made by a Vickers test machine into the cross section of the new agglomerates before the reduction test was observed. The results are shown in Fig. 9. Propagation of cracks which initiated from the indentation in the area of the return fines was observed, but no crack propagation

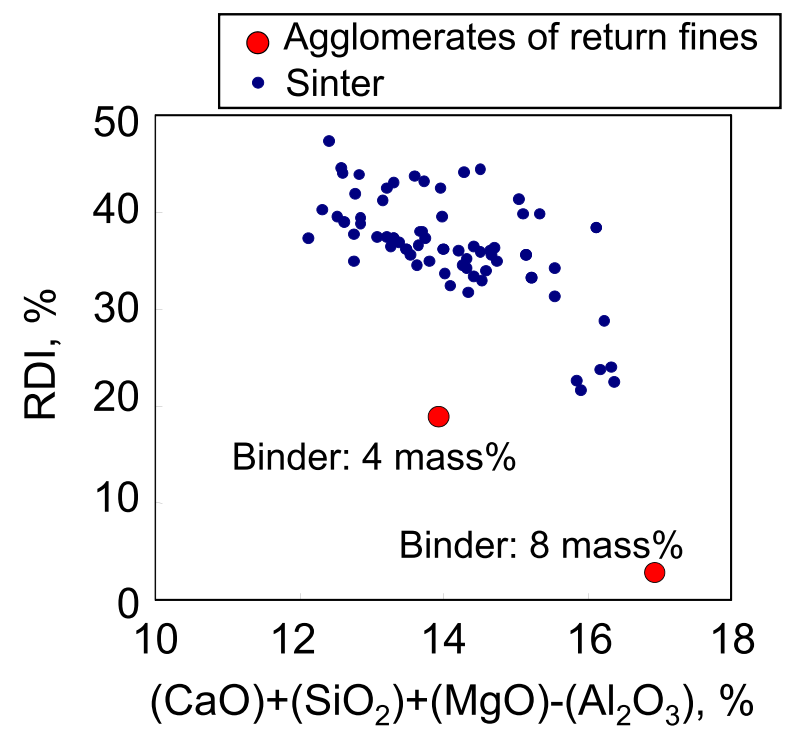

Fig. 7. Relationship between composition of raw material and RDI. (Online version in color.) 

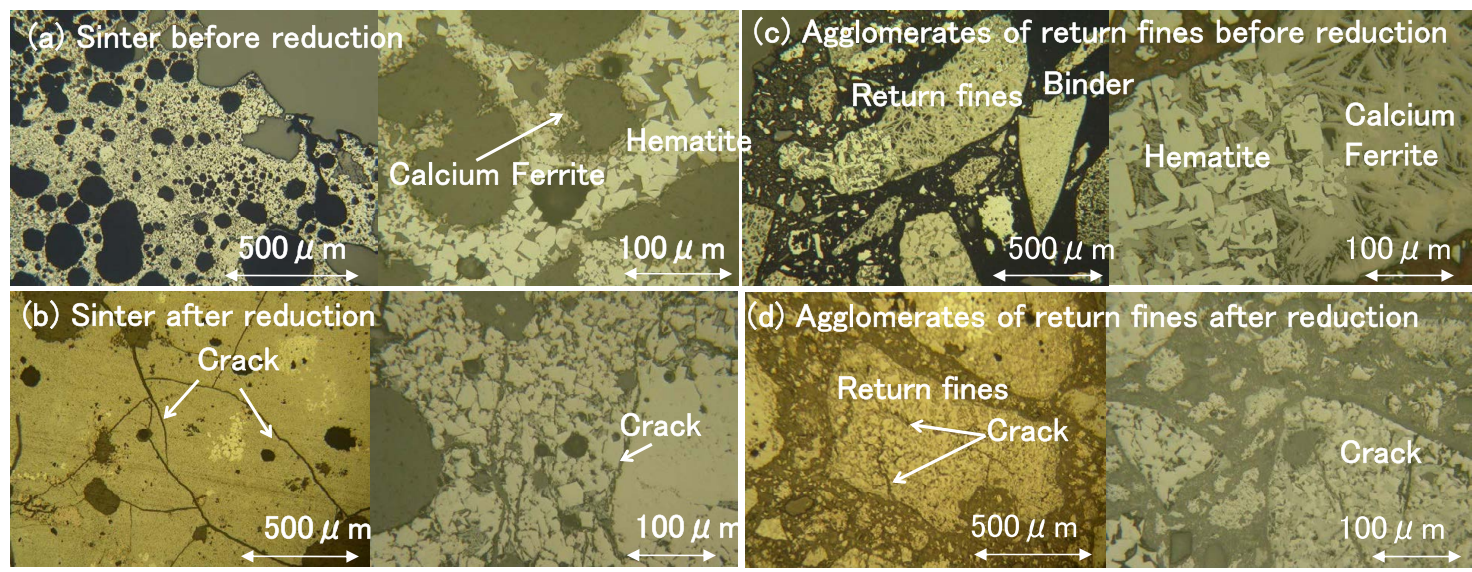

Fig. 8. Comparison of mineral structure between agglomerates of return fines and sinter. (Online version in color.)

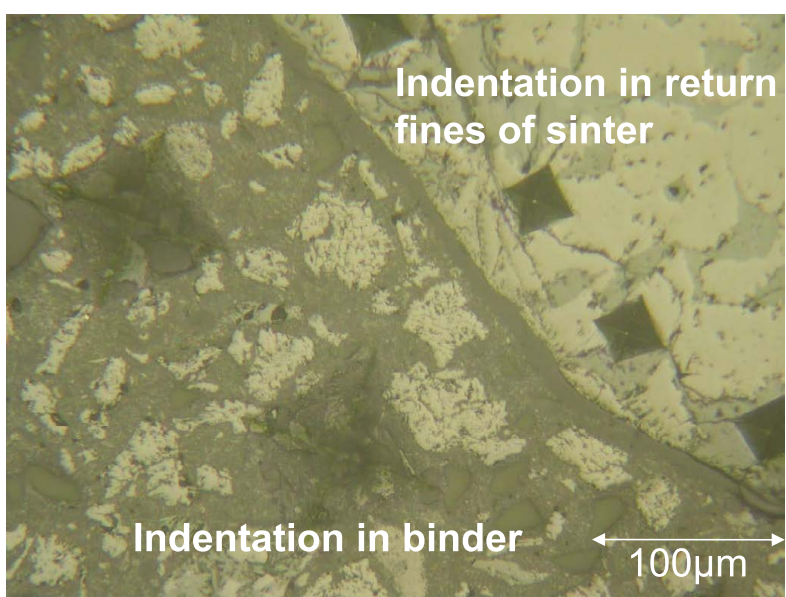

Fig. 9. Mineral structure of agglomerates of return fines after Vickers hardness test. (Online version in color.)

was observed in the binder area. Moreover, the size of the indentation in the binder area was larger than that in the return fines area; that is, the diagonal length of the indentation in the binder area was $99-110 \mu \mathrm{m}$, while that in the area of return fines was 38-40 $\mu \mathrm{m}$. The Vickers hardness in the binder area was calculated from the diagonal length of the indentation and compared with that in the return fines area. Since the Vickers hardness in the binder area was 0.15 times that in the return fines area, the binder area was significantly softer than the return fines area. From these experimental results, the brittle sinter in the new agglomerates is considered to be composed mainly of glassy silicate, but is arranged discretely and is joined by a soft binder. As a result, the new agglomerates are less brittle than the sinter, and RDI is decreased because crack propagation in the temperature region where reduction degradation occurs is prevented.

In order to investigate the reason why the RI of the new agglomerates was higher than that of the sinter, the distribution of the pore diameter in the new agglomerates and sinter was investigated. The results are shown in Fig. 10. The ratio of micropores with diameters of under 15 $\mu \mathrm{m}$ is higher in the new agglomerates than in the sinter. Yamaguchi et al. ${ }^{15,16)}$ investigated the JIS-RI and reduction ratio obtained at $1000^{\circ} \mathrm{C}\left(\mathrm{R}_{1000}\right)$ of sinter, iron ore and pellets, and reported that JIS-RI and $\mathrm{R}_{1000}$ are increased by

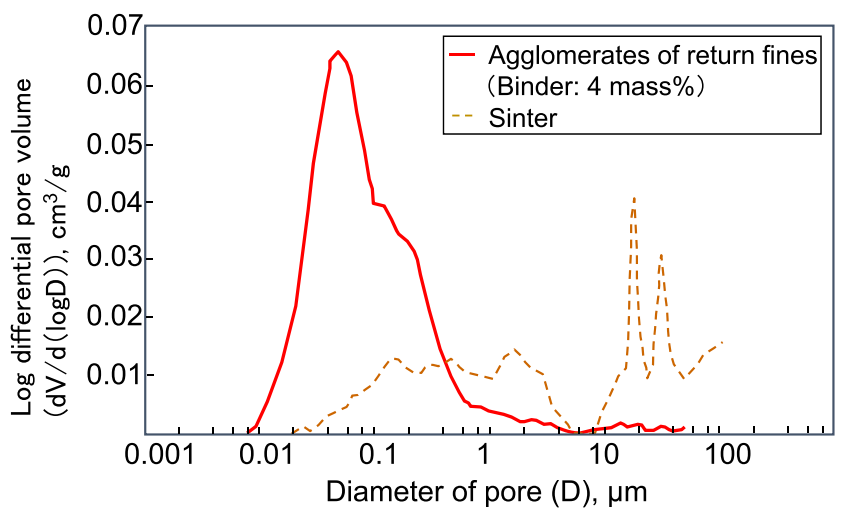

Fig. 10. Distribution of pore diameter in agglomerates of return fines and sinter. (Online version in color.)

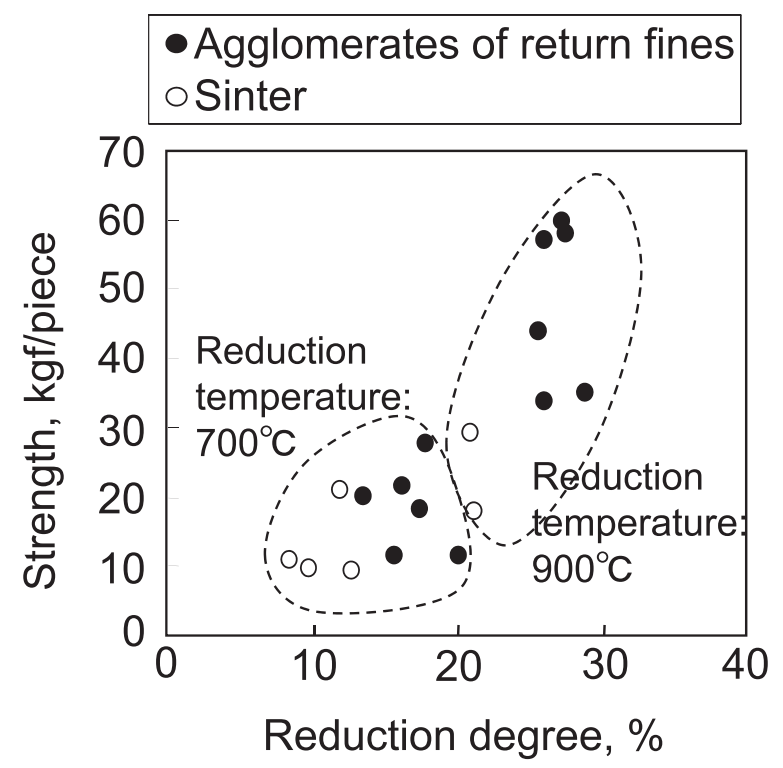

Fig. 11. Strength of agglomerates of return fines and sinter after reduction test.

increasing the amount of micropores with sizes under 15 $\mu \mathrm{m}$ because reduction in the solid phase is promoted by an exponential increase in the specific surface area. Based on those experimental results, it is considered that the reducibility of the new agglomerates is improved not only by the use of finer sinter having a large specific surface area, but 
also by the high ratio of micropores with diameters under $15 \mu \mathrm{m}$ in the particles of the new agglomerates.

The compressive strength of the new agglomerates after reduction was investigated in comparison with that of the sinter. As the reduction conditions, the composition of the reducing gas was $\mathrm{CO}: \mathrm{CO}_{2}: \mathrm{N}_{2}=0.25: 0.25: 0.5$, the reduction temperatures were $700^{\circ} \mathrm{C}$ and $900^{\circ} \mathrm{C}$ and the reduction time was $30 \mathrm{~min}$. The reduction ratio was calculated from the weight decrease after reduction, which was obtained by eliminating the weight decrease of the binder in the same manner as in the RI measurements. The results are shown in Fig. 11. When compared at the same reduction temperature, the reduction ratio of the new agglomerates was higher than that of the sinter, and the compressive strength of the new agglomerates was also higher than that of the sinter, especially when the reduction temperature was $900^{\circ} \mathrm{C}$. This is because the reduction ratio was increased by the higher ratio of micropores in the new agglomerates in comparison with the sinter, and compressive strength after reduction was improved by solid phase sintering of the ultrafine iron oxide in the new agglomerates, even under a reducing atmosphere.

\section{Conclusion}

Cold agglomeration of return fines of sinter was performed using cement and fine powder of blast furnace slag as binders, and reduction tests of the new agglomerates were carried out. The following findings were obtained.

- The new agglomerates have lower RDI $(\mathrm{RDI}<20 \%)$ and higher RI (DI $>70 \%)$ than sinter. As the reason for the lower RDI, it is considered that the new agglomerates are less brittle than sinter because the brittle sinter is arranged discretely in the new agglomerates and is bonded by a soft binder. The reason for the higher RI is considered to be the higher ratio of micropores in the new agglomerates in comparison with sinter.

- The compressive strength of the new agglomerates after reduction at $700^{\circ} \mathrm{C}$ and $900^{\circ} \mathrm{C}$ is equal to or higher than that of sinter. This increase of compressive strength is thought to be caused by solid phase sintering of the ultrafine iron oxide powder added to the raw material mix.

Therefore, the new agglomerates of return fines of sinter have superior properties of permeability and reducibility for blast furnace operation in comparison with sinter.

\section{REFERENCES}

1) S. Shono, K. Ito and S. Oobuchi: Tetsu-to-Hagané, 49 (1963), 330 (in Japanese).

2) M. Nakamura, T. Sawada, K. Nakamura, T. Minagawa, Y. Tagawa and H. Takahashi: Tetsu-to-Hagané, 72 (1986), S875 (in Japanese).

3) R. Nakajima, S. Kishimoto, A. Yamaguchi, T. Sawada, K. Nemoto and R. Toshimitsu: NKK Giho, 126 (1989), 9 (in Japanese).

4) M. Gocho, S. Kishimoto, A. Maki, M. Nozawa, K. Kikuchi and M. Hamaya: CAMP-ISIJ, 5 (1992), 1062 (in Japanese).

5) A. Suzawa, R. Naganawa, H. Maeda, K. Noshima, T. Inazumi and M. Aida: Tetsu-to-Hagané, 65 (1979), S576 (in Japanese).

6) S. Mizuno, S. Nagami, T. Miyake, J. Nomi, T. Shigematsu and Y. Iwanaga: Tetsu-to-Hagané, 68 (1982), S767 (in Japanese).

7) S. Takagi, H. Maeda, A. Yumura, K. Takatani, T. Ohsawa, Y. Fujiwara and K. Mio: Tetsu-to-Hagané, 72 (1986), S886 (in Japanese).

8) H. Yokoyama, K. Higuchi, T. Ito and A. Oshio: Tetsu-to-Hagané, 100 (2014), 601 (in Japanese).

9) S. Kabuto, K. Nishikawa, H. Yoshida, S. Matsunaga, M. Kobayashi and K. Oka: CAMP-ISIJ, 10 (1997), 14 (in Japanese).

10) A. H. M. Andreasen: Kolloid-Z., 50 (1930), 217.

11) T. Kosuge, K. Kodama and T. Horio: Tetsu-to-Hagané, 52 (1966), 498 (in Japanese).

12) T. Kawaguchi, T. Inazumi, S. Kasama and K. Sato: CAMP-ISIJ, 3 (1990), 1066 (in Japanese)

13) M. Sasaki, T. Enokido, S. Kondo and T. Nakazawa: Tetsu-to-Hagané, 59 (1973), 1209 (in Japanese).

14) N. Sakamoto, H. Fukuyo, Y. Iwata and T. Miyashita: Tetsu-toHagané, 70 (1984), 512 (in Japanese).

15) K. Yamaguchi, K. Higuchi, Y. Hosotani, A. Ohshio and S. Kasama: Tetsu-to-Hagané, 84 (1998), 702 (in Japanese).

16) K. Yamaguchi: Koro-wo-Sasaeta-Sogyogizyutsu-to-Gennenryo (Progress of Operation Technologies and Raw Materials for Blast Furnace), Tohoku University Press, Sendai, (2001), 79 (in Japanese). 